\title{
A Study in Enhancing L2 Learners' Utility with Written Academic Formulaic Sequences
}

Lewis Murray

Intervention exercises have tended to be limited to restricted controlled output in studies related to second language (L2) learners' acquisition of written academic formulaic sequences (FSs), while measurement of use has been drawn from freer output (AlHassan $\mathcal{E}$ Wood, 2015; Jones E Haywood, 2004; Peters $\mathcal{E}$ Pauwels, 2015). The current study reports on an intervention designed to be less controlled than previous studies and therefore closer to what learners would subsequently be required to produce. The intervention required a treatment group to edit target FSs into given paragraphs. These paragraphs were similar to those they were later required to produce and from which the data were drawn. Data drawn from pretests established that there was no significant difference in the occurrence of target FSs use between the treatment and control groups. Data drawn from posttests were used to determine whether there was any significant difference in the occurrence of the target FSs between pre- and posttests for each group. Results from the treatment group indicate that the intervention appears to have been effective in increasing learners' utility with the target FSs.

Les exercices d'intervention ont eu tendance à être limités à la production restreinte et contrôlée dans des études liées à l'acquisition de formules académiques écrites en L2, alors que la mesure de l'emploi a été tirée d'une production plus libre (AlHassan \& Wood, 2015; Jones \& Haywood, 2004; Peters \& Pauwels, 2015). La présente étude rend compte d'une intervention conçue de sorte à être moins contrôlée que les études précédentes et donc plus près de ce que les étudiants auraient à produire par la suite. L'intervention exigeait qu'un groupe expérimental révise les formules ciblées pour former des paragraphes. Ces paragraphes étaient similaires à ceux qu'ils devaient produire par la suite et à partir desquels les données étaient puisées. Les données de pré-tests ont établi qu'il n'y avait aucune différence significative dans l'emploi de formules ciblées chez le groupe expérimental et chez le groupe témoin. Les données des post-tests ont déterminé s'il y avait des différences significatives dans l'emploi des formules ciblées entre le pré-test et le post-test pour les deux groupes. Les résultats du groupe expérimental indiquent que l'intervention semble avoir augmenté l'emploi par les étudiants des formules ciblées.

KEYWORDS: Formulaic sequences; vocabulary acquisition; academic writing

The ubiquity of formulaic language within various fields of discourse has been well documented by corpus studies (Meunier, 2012), and has been 
found to be highly prevalent within the field of academic writing (see AlHassan \& Wood, 2015, p. 52). Studies have also shown that particular formulaic sequences (FSs), defined here as "combinations of words that fulfil specific functions and that are called up more or less automatically by native speakers" (Adel and Erman, 2012, p. 81), are more likely to occur within particular discourse genres. This in turn suggests that proficiency in a given genre requires knowledge of its preferred FSs, and that incorrect usage signals unfamiliarity. Therefore, clear value can be seen in developing second language (L2) learners' knowledge of FSs. To this end a number of studies have sought to uncover what might be the most useful FSs within academic writing (see, for example, Hyland, 2008; Martinez \& Schmitt, 2012; Simpson-Vlach \& Ellis, 2010), yet, as Coxhead (2008) notes, relatively few have touched on pedagogical implications.

This study seeks to redress this imbalance somewhat by examining the value of an intervention intended to enhance learners' utilization of target FSs within an academic writing context. Simpson-Vlach and Ellis (2010) propose frequency of occurrence as the primary factor in L2 learners' determination of formulaicity, while Conklin and Schmitt (2012) claim frequency of exposure to be a "key aspect of learning formulaic sequences" (p. 56). Cortes (2004), however, argues that frequency of exposure is insufficient for acquisition, claiming that noticing is also crucial. Likewise, Coxhead (2008) proposes that providing tasks that require target items to be used may be beneficial, a sentiment echoed by Peters and Pauwels (2015), who tentatively conclude in favour of cued output activities as a means of improving learners' use of FSs. It is with these factors in mind that the current study was designed, namely to gauge what effect encouraging learners to integrate target FSs into texts might have on their subsequent use of these items.

\section{Literature}

In surveying the field of L2 learners' FS acquisition, Boers and Lindstromberg (2012) comment that the benefits to learners of mastering formulaic language are increasingly apparent, but that "the learning challenge is daunting [as] ... learners must achieve both breadth and depth of knowledge" (p. 88). AlHassan and Wood (2015) also note the "vital role" (p. 52) FSs play in L2 learners' language competence, while Peters and Pauwels (2015) suggest that misuse can make them sound "odd and non-native-like" (p. 29), going on to note that within academic writing, L2 learners have been shown to overuse FSs more appropriate to spoken discourse. Siepmann (2008) also claims that analyses of L2 learners' discourse reveal greater use of a more limited number of FSs than is found in native speaker discourse, and of single words to express functions more commonly expressed by FSs, characteristics also reported by Cortes (2004) and Ellis (2012). 
The above may be seen to establish both the value of proficiency with FSs and the difficulties L2 learners are found to encounter in successfully using them. In terms of pedagogical interventions, a number of methods have been investigated, such as encouraging noticing of target FSs through typographical enhancement, glossing, and text flooding (see Boers and Lindstromberg, 2012, for a more extensive review). In many of the studies Boers and Lindstromberg (2012) report on, learners' subsequent acquisition of target sequences was measured through recall or recognition, but not through use within freely produced discourse. More recently, Lindstromberg, Eyckmans, and Connabeer (2016) used a modified dictogloss intended to highlight target FSs, finding that learners given the modified version used more of the target sequences in the reproduction stage, but again reproduction was measured in controlled output.

In contrast, the following three studies-Jones and Haywood, 2004; Peters and Pauwels, 2015; AlHassan and Wood, 2015-each sought to measure the effectiveness of explicit instruction of written academic FSs, in part through the occurrence of target items in participants' writing. With data drawn from freer output than many of the studies covered by Boers and Lindstromberg (2012), they are of particular significance within the present study. In the first of these, Jones and Haywood (2004) employed various exercises designed to familiarize learners with target FSs, measuring familiarity in terms of awareness, controlled output, and freer output. They note that two hours per week over a 10-week course were devoted to teaching FSs. Pre- and posttests were used to measure gains, with data from the treatment group compared with a control group. While gains were made in learners' awareness and controlled output, "improvement in the use of phrases in their essays was less noticeable" (Jones \& Haywood, 2004, p. 289).

Peters and Pauwels (2015) carried out a similar study, with the additional aim of investigating which method of instruction proved most beneficial in terms of the same three areas as Jones and Haywood (2004), namely recognition, cued output, and spontaneous use. The 24 FSs selected for the study were divided equally into three input categories: recognition activities, cued output activities, and recognition and cued output activities, with the treatment carried out over three consecutive sessions "mainly devoted to academic FS" (Peters \& Pauwels, 2015, p. 32). These were then assigned to the treatment group, whose recognition and use of the target items was measured through pre- and posttests, with the authors tentatively concluding that "activities involving cued output exercises might be more beneficial" (p. 37). While the greatest gains were found in terms of participants' recognition of target items, they also report that the occurrence of target FSs was significantly greater in participants' end-of-year assignments than in those who had not received explicit instruction.

Finally, AlHassan and Wood (2015) examined the effects of ten 90-minute sessions of focused instruction of FSs on students' academic writing. Instruc- 
tion exercises consisted of both decontextualized practice with target FSs, such as requiring their use in rewriting example sentences, and contextualized practice exercises, such as requiring target items be used in stand-alone sentences responding to prompts, similar to the test prompts. Their data revealed significantly increased use of target FSs between pre- and posttests, with the increased use seen to enhance evaluations of participants' academic writing. AlHassan and Wood (2015) attribute the relative scarcity of FSs within the pretests to learners not being explicitly taught how to successfully and appropriately incorporate FSs into their writing.

Two elements common to each of the above studies are of particular relevance to the present study. First, in all three, extended periods of class time were devoted exclusively to instruction of the target FSs. The present study, however, was conducted over the course of an 8-week academic writing class consisting of one 90-minute session a week, during which various elements relating to paragraph writing had to be addressed. As such, devoting extended periods of class time to instruction in FSs was not possible. It was necessary instead to find possible methods of integrating this instruction within the overall program and provide opportunities for practice without neglecting other syllabus objectives. In this respect, it is likely more similar to the situation normally encountered on EAP courses; Coxhead (2008) highlighted time constraint as a particular issue within the context.

Second, while each of the three studies measured participants' proficiency with the target items through use in written paragraphs, the production exercises employed in each appear to be limited to more controlled use. Peters and Pauwels (2015), for example, note that their "use in a sentence" exercises, which fall at the freer end of cued output, "can be considered a limited form of creative use" (p. 33). Likewise, AlHassan and Wood (2015) state that participants "had to practice the use of the target FSs in uncontrolled production by using them in meaningful sentences" (p. 54). Examples of similar exercises in which specified FSs were required to be used in sentences are also provided by Jones and Haywood (2004, p. 298). While exercises of this sort may require that learners are familiar with the meaning and function of a given FS, it is still arguably something of a leap from such explicit prompting and decontextualized usage to free use within the learner's own writing.

The present study attempts to address the above points regarding time constraint and freer production at the practice stage by examining what effect editing target items into texts may achieve. In order to examine the efficacy of this intervention, a two-stage study was designed. The first stage aimed to familiarize participants with the target FSs, while the second required participants to edit target items into texts before examining what effect this activity might have on participants' free use of the target FSs in their writing. The study was guided by the following research question:

Does an explicit focus on integrating target FSs into paragraphs affect learners' subsequent use of these items in their own writing? 


\section{Method}

\section{Population}

The population comprised four groups, herein named Group A, Group B, Group C and Group D, consisting of 28, 30, 28, and 29 learners respectively (these are the numbers from whom data were drawn). Each group constituted a class of first-year undergraduate students at a national university in Japan. Classes were formed on the basis of the students' major, not proficiency level, so while each group was approximately CEFR level B1 (an estimation based on the university entrance exam students had recently passed), this varied between individual students within each class. All groups were required to take the same 8-week academic writing course, and all were taught by the researcher. A control group comprising 54 participants (in two classes) was also used as a means of comparison. Students in the control group were also assigned to class on the basis of their major, with each class being of approximately the same overall proficiency level as the treatment groups. They were also taking the same 8-week academic writing course at the same university as those in the treatment groups, but were taught by a different instructor. As the syllabus for the writing course was fixed, treatment group and control group participants followed the same weekly content, with the exception of the intervention described below. The treatment groups and the control group also used the same textbook, Longman Academic Writing Series 2: Paragraphs (Hogue, 2014).

\section{Target Items}

A total of 16 FSs were selected (see Table 1), each serving a clear pragmatic function within written academic discourse. The selection criteria required that each FS be present in either the Phrasal Expressions List (PHRASE; Martinez \& Schmitt, 2012) or the Academic Formulas List (AFL; SimpsonVlach \& Ellis, 2010), and, following the rate used by Cortes (2004), occur at least 20 times per million words within the 6.5-million-word corpus of British Academic Written English (BAWE; University of Oxford Text Archive, 2014). As is clear in Table 1, 10 of the 16 items selected appear in both lists, while the frequency rate of all but three of the FSs was more than double the cut-off rate. The function served by each of the target items also factored into selection, with those chosen seen to be of maximal value within the context.

\section{Treatment}

The treatment was divided into two stages, with Stage 1 (Weeks 1 to 3) aimed at familiarizing learners with the target FSs and Stage 2 (Weeks 5 to 7) aimed at enhancing learners' utilization of them. 


\section{Stage 1}

Within Stage 1, target items were offered three times over the 3-week treatment period, each time within the context of a paragraph, similar to that which the learners would be required to produce. Three different activities, each utilizing the same paragraphs, were used as a means of introducing the target FSs: cut-up paragraphs with target items in bold text that learners, working together in groups of three, were required to reorder (Method 1); a closed gap-fill exercise with the target items removed and listed above the text (Method 2); and a matching activity, requiring target items to be matched with their function, listed below the texts (Method 3) (see Appendix A for an example worksheet). Table 2 shows the method assigned to each of the four treatment groups for the duration of Stage 1. It is worth noting that assignment was random. In line with Boers, Demecheleer, Coxhead, and Webb (2014), target items were presented intact, rather than being broken down into their component words within each of the three exercise types. All three activities also required engagement with the target items for completion, with two (Method 2 and Method 3) requiring that they be reproduced, a factor Coxhead (2008) suggests may be beneficial. Methods 1 and 2 were car-

Table 1

The Target FSs Selected

\begin{tabular}{lrrrr}
\hline & BAWE & BAWE (approx. & & \\
& (raw frequency) & count per million) & PHRASE & AFL \\
\hline On the other hand & 840 & 129 & $\mathrm{X}$ & $\mathrm{X}$ \\
In contrast (to) & 496 & 76 & $\mathrm{X}$ & \\
In terms of & 1734 & 266 & $\mathrm{X}$ & $\mathrm{X}$ \\
With respect to & 320 & 49 & $\mathrm{X}$ & $\mathrm{X}$ \\
To some extent & 163 & 25 & $\mathrm{X}$ & $\mathrm{X}$ \\
As well as & 2368 & 364 & & $\mathrm{X}$ \\
In other words & 338 & 52 & $\mathrm{X}$ & $\mathrm{X}$ \\
In order to & 3991 & 614 & & $\mathrm{X}$ \\
Whether or not & 251 & 38 & $\mathrm{X}$ & $\mathrm{X}$ \\
For example & 3335 & 513 & & $\mathrm{X}$ \\
A number of & 1158 & 178 & $\mathrm{X}$ & $\mathrm{X}$ \\
As a result & 1278 & 196 & $\mathrm{X}$ & $\mathrm{X}$ \\
In addition to & 393 & 60 & $\mathrm{X}$ & \\
Can be seen & 1245 & 191 & & $\mathrm{X}$ \\
At the same time & 507 & 78 & $\mathrm{X}$ & $\mathrm{X}$ \\
In the same way & 213 & 32 & $\mathrm{X}$ & $\mathrm{X}$ \\
\hline
\end{tabular}

The frequency of target items (raw and per million words) within BAWE, and the presence of each $(\mathrm{X})$ within PHRASE and AFL. 
ried out in class, with approximately 10 minutes allotted each week, while Method 3 was set as homework. Answer keys for each of the methods were provided, enabling participants to check individually upon completion.

Table 2

Method Assigned to Each Treatment Group in Stage 1

\begin{tabular}{ll}
\hline Treatment group & Method assigned \\
\hline A & Method 1 \\
B & Method 1 \& 3 \\
C & Method 2 \\
D & Method 2 \& 3 \\
\hline
\end{tabular}

\section{Stage 2}

Stage 2 of the treatment was conducted in Weeks 5, 6, and 7, following the midterm, with the same activities carried out across each of the four treatment groups. In each week, participants were given a worksheet, at the top of which all 16 target items were presented with the first letter of each word followed by a number of dashes corresponding to the missing letters (e.g., I_I $t_{---} / o_{-}=$in terms off). The order of the target items was changed each week to deter simple copying of the previous week's worksheet. After completing the worksheet, participants were asked to write the items on the board as a means of checking. This served the additional purpose of making the target items visible for the remainder of the lesson, during which "editing" of the FSs into example paragraphs and the learners' own texts was conducted. Typically, this exercise required approximately five minutes of class time.

The editing exercises entailed learners taking example paragraphs and, in many instances, paragraphs they had written themselves, and editing target FSs into the texts where possible (see Appendix B for an example). While the constraints of the paragraphs did not allow for entirely free use of the target items, the activity arguably belongs at the freer end of cued output. Learners were also instructed to use, where possible, alternative target items to convey particular functions rather than repeat the same item. Feedback was provided in the form of a model example, with learners encouraged to suggest alternative changes. Whole-class activities of this sort were often followed by learners applying the same editing techniques to their own homework assignment paragraphs, during which the instructor was able to check individuals' progress. Through such exercises, it was hoped that learners would better appreciate how the target items might be utilized in favour of less genre-appropriate language serving a similar function to enhance their writing. No fixed time was allotted to the above editing exercises as they were carried out alongside other paragraph editing activities, such as formatting and combining sentences. 


\section{Measurement}

Data were drawn from participants' midterm and final papers, with all participants required to produce the same length and type of paper for each (the midterm was a 150-word listing order paragraph completed at home, the final a 300-word opinion paragraph completed in class). First, AntConc (Anthony, 2016) was used to identify occurrences of target items in midterm and final papers. The frequency of target items per 200 words was then calculated within each paper from participants in both the treatment group and control group. As the distributions within each group were found to be not normal, nonparametric tests were used. A Mann-Whitney test was run to determine whether there was any significant difference between the treatment group and control group in terms of occurrences of target items in the midterm. Wilcoxon signed-rank tests were then run to compare target item usage between the midterm and the final of both the treatment group and control group. These established whether there was any significant difference in the rate of usage between the midterm and final within each group.

\section{Data Analysis}

As is apparent from Figure 1, frequency of use (per 200 words) of the target items within the midterm papers in both the treatment group $(M d n=1.28)$ and the control group $(M d n=0)$ was low. A Mann-Whitney test determined that they did not differ significantly, $U=2864.5, z=-.846, p=.398, r=-.065$. As there was no significant difference between the two groups' midterm usage, it was therefore appropriate to compare target item occurrence within the midterm and final data from both the treatment group and the control group

Target FSs per 200 words (Median score)

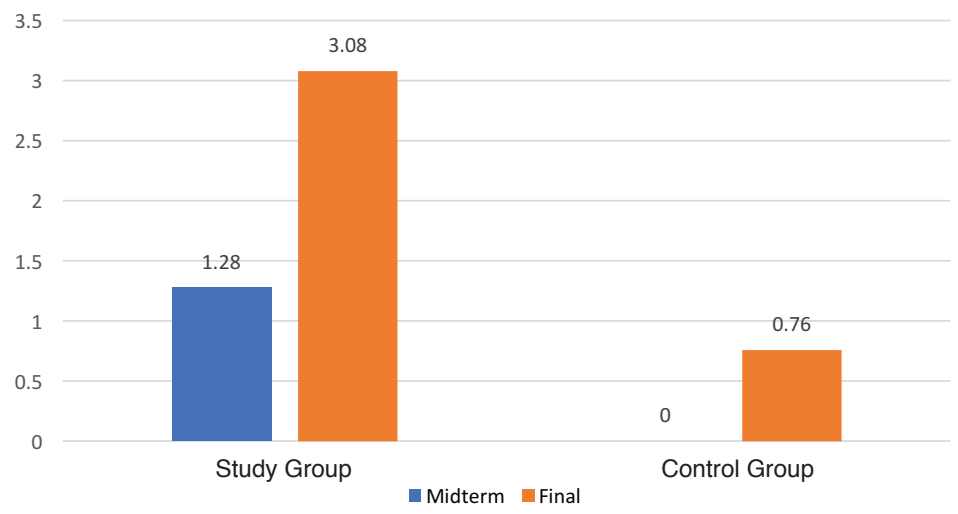

Figure 1: The median score for the occurrence of target FSs within both the treatment and control groups' midterm and final papers. 
to determine whether differences there might be significant. Gains made by the control group between the midterm $(M d n=0)$ and the final $(M d n=0.76)$ were not significant, $T=524, p=.857, r=-.17$. However, gains made by the treatment group between the midterm $(M d n=1.28)$ and the final $(M d n=3.08)$ were significant, $T=477, p<.001, r=-.52$.

As no pretest was carried out prior to Stage 1 to determine participants' level of use before carrying out the familiarization exercises, it is not possible to say with any authority what impact these exercises had. However, the data from the midterm papers show that after the more controlled exercises carried out in Stage 1, there was no significant difference between the treatment group and control group in terms of usage of target FSs. In contrast, the data drawn from final papers produced by the treatment group after Stage 2 of the treatment show a significant increase in usage compared to the midterm. This suggests that the significant effect observed in the treatment group was the result of the activities carried out in Stage 2 of the treatment.

Table 3 provides more detail than is available in Figure 1, showing the occurrence of each of the target FSs per 4000 words within both the midterm

Table 3

The Frequency per 4000 words for Each of the Target FSs

\begin{tabular}{|c|c|c|c|c|c|c|c|c|c|c|}
\hline & \multicolumn{2}{|c|}{$\begin{array}{c}\text { Group A } \\
(n=28)\end{array}$} & \multicolumn{2}{|c|}{$\begin{array}{l}\text { Group B } \\
(n=30)\end{array}$} & \multicolumn{2}{|c|}{$\begin{array}{l}\text { Group C } \\
(n=28)\end{array}$} & \multicolumn{2}{|c|}{$\begin{array}{l}\text { Group D } \\
(n=29)\end{array}$} & \multicolumn{2}{|c|}{$\begin{array}{l}\text { Control } \\
(n=54)\end{array}$} \\
\hline & MT & $\mathrm{F}$ & MT & $\mathrm{F}$ & MT & $\mathrm{F}$ & MT & $\mathrm{F}$ & MT & $\mathrm{F}$ \\
\hline Corpus word count: & 4245 & 8631 & 4762 & 9366 & 4419 & 8660 & 4579 & 9040 & 6912 & 13860 \\
\hline On the other hand & 0 & 1.4 & 4.2 & 3 & 1.8 & 1.8 & 0 & 1.3 & 2.9 & 0.6 \\
\hline In contrast to & 0 & 0.5 & 0 & 1.3 & 0 & 0.9 & 0 & 2.2 & 0 & 0 \\
\hline In terms of & 0.9 & 0.5 & 2.5 & 2.1 & 0.9 & 0.5 & 1.7 & 2.2 & 0.6 & 2.3 \\
\hline With respect to & 0 & 0.5 & 0 & 0 & 0 & 0 & 0.9 & 0.9 & 0 & 0 \\
\hline To some extent & 0 & 0.5 & 0 & 1.3 & 0 & 1.4 & 0 & 0.9 & 0 & 0 \\
\hline As well as & 0 & 2.8 & 1.7 & 3 & 0 & 4.2 & 3.5 & 5.8 & 0.6 & 0 \\
\hline In other words & 0.9 & 1.9 & 0 & 3.4 & 0 & 2.8 & 0 & 4.9 & 1.2 & 0.3 \\
\hline In order to & 0.9 & 4.2 & 1.7 & 4.7 & 0.9 & 4.6 & 0 & 3.5 & 2.3 & 1.2 \\
\hline Whether or not & 0 & 0 & 0 & 0 & 0 & 0.5 & 0 & 1.8 & 0 & 0 \\
\hline For example & 11.3 & 18.1 & 13.4 & 16.7 & 12.7 & 19.9 & 11.4 & 19 & 10.4 & 13.6 \\
\hline A number of & 1.9 & 3.2 & 0.8 & 1.7 & 0 & 3.7 & 3.5 & 11.1 & 0 & 0 \\
\hline As a result & 2.8 & 7.4 & 3.3 & 4.7 & 0 & 8.3 & 0 & 7.5 & 0.6 & 0 \\
\hline In addition to & 0.9 & 6 & 1.7 & 6.8 & 2.7 & 8.8 & 3.5 & 10.6 & 1.2 & 0.6 \\
\hline Can be seen & 0 & 2.8 & 0.8 & 1.3 & 0 & 1.4 & 0 & 1.8 & 0 & 0 \\
\hline At the same time & 0 & 4.6 & 2.5 & 5.1 & 0 & 4.6 & 0 & 1.3 & 0 & 0 \\
\hline In the same way & 0 & 1.4 & 0 & 1.3 & 0 & 0.5 & 0 & 1.8 & 0 & 0 \\
\hline Total: & 19.6 & 55.8 & 32.6 & 56.4 & 19 & 63.9 & 24.5 & 76.6 & 19.8 & 18.6 \\
\hline
\end{tabular}

$N=$ the population of each group. 
and final corpus of each group. Among the treatment groups, the data reveal that not only is the total occurrence of the target items considerably higher in the final than the midterm, but the variety of target items used is also greater. While the greater number of target items may be attributed to the extra length of the final assignment, it is clear from Figure 1 that the frequency (per 200 words) is also higher. The slightly different requirement of the two assignments may also factor into the difference, with the midterm being a listing order paragraph, and the final a reason and example paragraph. However, while the control group undertook the same assignments, the total occurrence of target items used by the control group between the midterm and final actually decreased. Furthermore, the variety of those used was actually less in the final. I would therefore argue that it was the editing activities carried out in Stage 2 of the treatment that may have been largely responsible for this increased use among the treatment groups. The following will examine instances where the explicit attention given to target items can be seen to have had a noticeable effect within the data shown above.

Being by far the most commonly used of the target items among all the groups, the first item deserving comment is for example. While this item is given explicit attention in the textbook, it is not given until chapter 5, which was not covered until after the midterm paper had been submitted. The high level of use among all groups within the midterm strongly suggests that the item was therefore familiar to learners before taking the course. Consequently, data relating to this item may be attributed to prior knowledge, and the higher levels of usage in the final paper a result of it being a reasons and examples paragraph, likely necessitating greater use than the midterm. While discounting these data has a considerable impact on the total number of items used, it is most noticeable in the control group, whose total drops from 9.4 target items per 4000 words in the midterm to 5 in the final. The same tests as were run previously to determine any significant difference between the two groups' midterm usage and increase between the midterm and final for each group were run again, excluding the data from "for example." As before, a Mann-Whitney test determined no significant difference between the two groups' midterm usage (treatment group $M d n=0$; control group $M d n=0$ ), $U$ $=2810.0, z=-1.455, r=-.11$. Likewise, a Wilcoxon signed-rank test determined there was no significant difference in use between the control group's midterm $(M d n=0)$ and final $(M d n=0), T=78, p=.115, r=-.12$, while the treatment group's midterm $(M d n=0)$ to final $(M d n=2.08)$ did show a significant difference, $T=146, p<.001, r=-.67$.

Another of the target items arguably affected by the textbook was in addition to. In this instance, while that exact item was not given in the textbook, in addition was-its high frequency throughout suggesting that, as with for example, it was likely familiar to participants prior to the study. As is clear from Table 4, among the treatment groups, the frequency of in addition was similar to for example in the midterm, with in addition to accounting for between $10 \%$ 
and $23 \%$ of these instances. However, in the final, this percentage changed dramatically, ranging from $50 \%$ to $85 \%$. Conversely, the control group's use dropped from $23 \%$ in the midterm (within the range of the treatment groups) to $7 \%$ in the final. While the treatment groups' ratio of utilization is considerably higher than in the native speaker comparison corpus, BAWE (University of Oxford Text Archive, 2014), the change in the rate of use between the midterm and final does suggest that the activities conducted in Stage 2 had some impact, helping to reinforce in addition to as a chunk. As well as, serving the same function as in addition to, was also among the target items, and was elicited from learners as an alternative in Stage 2. Table 4 shows that occurrences of this item among the treatment groups also increased between the midterm and final, further indicating that Stage 2 activities may have been beneficial.

Table 4

The Frequency per 4000 Words for Each of the Target FSs and in addition

\begin{tabular}{lrrrrrrrrrrr}
\hline Group: & \multicolumn{2}{c}{ A } & \multicolumn{2}{c}{ B } & \multicolumn{2}{c}{ C } & \multicolumn{2}{c}{ D } & \multicolumn{2}{c}{ Control } \\
& MT & F & MT & F & MT & F & MT & F & MT & F \\
\hline For example & 11.3 & 18.1 & 13.4 & 16.7 & 12.7 & 19.9 & 11.4 & 19 & 10.4 & 13.6 \\
In addition & 9.4 & 12 & 10.1 & 9.8 & 15.4 & 12.5 & 14.9 & 12.4 & 5.2 & 8.9 \\
In addition to & 0.9 & 6 & 1.7 & 6.8 & 2.7 & 8.8 & 3.5 & 10.6 & 1.2 & 0.6 \\
As well as & 0 & 2.8 & 1.7 & 3 & 0 & 4.2 & 3.5 & 5.8 & 0.6 & 0 \\
\hline
\end{tabular}

As a result was attended to in response to repeated incidences of thanks to that became apparent in the treatment groups' midterm corpora (see Table 5). This was addressed in feedback to the groups, with as a result elicited as an alternative. Although thanks to was still used in the final, frequency dropped across all four groups. At the same time, the frequency of as a result was greater in the final than the midterm. The frequency of thanks to decreased between the midterm and final for the control group too; however, the frequency of as a result also dropped.

Table 5

The Frequency per 4000 Words for the Target FS as a result and thanks to

\begin{tabular}{lrrrrrrrrrrr}
\hline Group: & \multicolumn{2}{c}{ A } & \multicolumn{2}{c}{ B } & \multicolumn{2}{c}{ C } & \multicolumn{2}{c}{ D } & \multicolumn{2}{c}{ Control } \\
& MT & F & MT & F & MT & F & MT & F & MT & F \\
\hline As a result & 2.8 & 7.4 & 3.3 & 4.7 & 0 & 8.3 & 0 & 7.5 & 0.6 & 0 \\
Thanks to & 2.8 & 1.4 & 2.5 & 1.3 & 2.7 & 1.4 & 2.6 & 1.3 & 1.7 & .9 \\
\hline
\end{tabular}

Two anomalies are also apparent in Table 2, the first of which relates to the high frequency of in terms of in the control group's final corpus. The instructor was consulted, stating that this item had been explicitly provided as 
a means of expressing a particular function within the concluding sentence of the paragraph, with an example of its use given. A check of the corpus revealed that, of eight instances, six were used in the same way within the concluding sentence, as per the instructor's example. Such usage might then be seen as the product of simple copying, as the evidence from the corpus gives no indication that the six learners who used the item in this way were able to use it beyond the limited context of the instructor's example. In contrast, the editing carried out by the treatment groups allowed participants to select target sequences based on function and appropriateness within the paragraph as a whole.

The second anomaly relates to the high incidence of a number of in the Group D final corpus. While this is considerably higher than in the other three treatment groups, a closer examination of the corpus reveals that, of a total of 25 instances, 5 and 7 counts respectively were found to occur within single assignments. The two papers in question might be seen to exemplify Siepmann's (2008) comment regarding overuse of particular items taken to the extreme, with the target item very clearly overused. That it only happens in two of the final essays also makes it clear that it was not a widespread issue, yet one that may be worth highlighting to learners.

\section{Discussion}

While the above has accounted for only a handful of the target items, it is clear from the data in Table 2 that the treatment groups' use of target items was, on the whole, greater in both frequency and variety after Stage 2 of the treatment. As not all of the items were attended to explicitly, the following will consider the apparent efficacy of the method employed. First, weekly exposure provided by the fill-the-blanks worksheet and subsequent boarding of the FSs ensured greater frequency of exposure to the target items, a factor proposed as being central to learners' determination and acquisition of FSs (Conklin \& Schmitt, 2012; Simpson-Vlach \& Ellis, 2010). Attending to them as discreet lexical items in this way should therefore have reinforced the items as chunks in learners' memories, evidence for which may be seen in the increased use of in addition to highlighted above. While this activity may be seen as simple rote learning, something Nesselhauf (2003) notes has "fallen into discredit" (p. 238), in discussing the teaching of collocations, she goes on to argue that it may be necessary. Likewise, Wray (2009) comments that while rote learning is seen to be acceptable in relation to single-word lexical items, if $\mathrm{L} 2$ learners are to achieve greater idiomaticity, it may also be beneficial for learning FSs.

The primary goal of this study, however, was not to have learners memorize a list of decontextualized FSs, but rather to explore what impact might be had from utilizing target items within texts similar to those participants were subsequently required to produce. In the three studies detailed above 
(AlHassan \& Wood, 2015; Jones \& Haywood, 2004; Peters \& Pauwels, 2015), acquisition was measured, at least in part, through participants' use of target items in their own writing. It was argued that there was a sizeable gap between the controlled nature of the acquisition exercises given within these studies and the free use from which data regarding target item usage was drawn. It was also noted that a substantial amount of time was devoted to participants' acquisition of target items in each of the studies, an element not usually available in EAP teaching contexts. The present study aimed to factor in both of these issues, providing controlled use in Stage 1 through activities requiring minimal lesson time. Although a pretest was not conducted, these appear to have had very little impact on treatment group participants' use of target FSs. Data drawn from the midterms, produced following Stage 1 , revealed no significant difference between the treatment groups and the control group. The exercise sheets in Stage 2, requiring participants to fill in the gapped target items, provided further consolidation of the target FSs, thereby priming learners for the final stage of integration. In this latter stage, participants were required to edit target items, where possible, into texts. It was hoped that this would provide a less controlled output context than in the studies highlighted, and also be closer to what participants were subsequently required to produce. Participants were also encouraged to integrate target items into passages they themselves had written, either in class or as homework assignments. As noted above, it was possible to conduct the activities at this stage alongside other paragraph editing activities.

The significant gains made by the treatment groups between the midterm and final, apparent in Figure 1, suggest that the editing activities were successful in enhancing participants' use of the target FSs. Such activities allowed learners to appreciate how multiple FSs might be used in context, rather than attending to single items within decontextualized sentences. Furthermore, by requiring that learners choose which of the target items may be most appropriate at which point in a given text, some level of critical engagement, with both the target items and the text as a whole, was required. This arguably contrasts with the majority of occurrences of in terms of in the control group corpus, noted above, which appear to indicate instead a very limited knowledge of the item's function beyond a single instance. If, as AlHassan and Wood claim, the use of FSs can be seen to form "the skeleton of L2 Learners' proficient academic writing" $(2015$, p. 61), seeing the role they perform within a larger body of discourse is surely vital. If, however, they are only encountered in decontextualized sentences, it doesn't seem possible that learners will appreciate this. Learning to apply FSs in context, as was practiced here, may be seen to enhance such an appreciation. Moreover, that this element of EAP writing was attended to within the overall context of the writing course allowed for other course objectives to be addressed simultaneously.

Finally, as this study only examined the use of a limited number of target items, it could be the case that other FSs were used by the control group. 
However, target items were chosen because of their high frequency within academic written discourse, and could therefore be expected to occur with frequency in native-like discourse of this genre. If the purpose of the writing class in question was to improve learners' academic written English, this is arguably not being achieved by failing to include this element. If, as was highlighted above, one of the functions of FSs is to signal membership in a particular discourse community, this study suggests that the process may be significantly enhanced by explicitly introducing learners to the language expectations of the genre, and scaffolding the integration of such language through the methods outlined above. Furthermore, while participants' knowledge of the target items prior to the treatment was not measured, allowing for no gauge of the efficacy of the Stage 1 interventions, the study indicates that explicit attention to these items, and encouraging their use, appear to have a significant effect.

\section{Conclusion}

This study aimed to add to the small but growing body of work exploring ways in which L2 learners' use of FSs in an academic writing context might be increased, through seeking to examine the efficacy of editing target items into existing texts. It was hoped that this activity, being of a less controlled nature than many of those used in previous studies, might be more beneficial in encouraging participants' greater use of the target items in their own writing. The data reveal that frequency of use of the target items by the treatment groups was found to be significantly higher in the final than in the midterm, in comparison to the control group, where no significant gains were seen over the same period. This increased use of the target FSs in the final suggests that the editing activities carried out subsequent to the midterm were successful in terms of acquisition. Furthermore, through utilizing extended passages of text rather than isolated sentences, the editing activities could be easily addressed simultaneously with other elements of paragraph writing, arguably making them of more value within an EAP context.

\section{The Author}

Lewis Murray currently teaches English at Kanazawa University, Japan. His research interests focus primarily on formulaic language in relation to L2 learners' acquisition.

\section{References}

Adel, A., \& Erman, B. (2012). Recurrent word combinations in academic writing by native and non-native speakers of English: A lexical bundles approach. English for Specific Purposes, 31(2), 81-92. https://doi.org/10.1016/j.esp.2011.08.004

AlHassan, L., \& Wood, D. (2015). The effectiveness of focused instruction of formulaic sequences in augmenting L2 learners' academic writing skills: A quantitative research study. Journal of English for Academic Purposes, 17, 51-62. https://doi.org/10.1016/j.jeap.2015.02.001

Anthony, L. (2016). AntConc 3.4.4w [Computer Software]. Retrieved from http://www.antlab.sci. waseda.ac.jp/antconc_index.html 
Boers, F., Demecheleer, M., Coxhead, A., \& Webb, S. (2014). Gauging the effects of exercises on verb-noun collocations. Language Teaching Research, 18(1), 54-74. https://doi. org/10.1177/1362168813505389

Boers, F., \& Lindstromberg, S. (2012). Experimental and intervention studies on formulaic sequences in a second language. Annual Review of Applied Linguistics, 32, 83-110. https://doi. org/10.1017/S0267190512000050

Conklin, K., \& Schmitt, N. (2012). The processing of formulaic language. Annual Review of Applied Linguistics, 32, 45-61. https://doi.org/10.1017/S0267190512000074

Cortes, V. (2004). Lexical bundles in published and student disciplinary writing: Examples from history and biology. English for Specific Purposes, 23(4), 397-423. https://doi.org/10.1016/j. esp.2003.12.001

Coxhead, A. (2008). Phraseology and English for academic purposes: challenges and opportunities. In F. Meunier \& S. Granger (Eds.), Phraseology in foreign language learning and teaching (pp. 149-161). Amsterdam, Netherlands: John Benjamins.

Ellis, N. C. (2012). Formulaic language and second language acquisition: Zipf and the phrasal teddy bear. Annual Review of Applied Linguistics, 32, 17-44. https://doi.org/10.1017/ S0267190512000025

Hogue, A. (2014). Longman academic writing series 2: Paragraphs (3rd ed.). New York, NY: Pearson Education.

Hyland, K. (2008). As can be seen: Lexical bundles and disciplinary variation. English for Specific Purposes, 27(1), 4-21. https://doi.org/10.1016/j.esp.2007.06.001

Jones, M., \& Haywood, S. (2004). Facilitating the acquisition of formulaic sequences: an exploratory study in an EAP context. In N. Schmitt (Ed.), Formulaic sequences: Acquisition, processing and use (pp. 269-300). Amsterdam, Netherlands: John Benjamins.

Lindstromberg, S., Eyckmans, J., \& Connabeer, R. (2016). A modified dictogloss for helping learners remember L2 academic English formulaic sequences for use in later writing. English for Specific Purposes, 41, 12-21. https://doi.org/10.1016/j.esp.2015.08.002

Martinez, R., \& Schmitt, N. (2012). A phrasal expressions list. Applied Linguistics, 33(3), 299-320. https://doi.org/10.1093/applin/ams010

Meunier, F. (2012). Formulaic language and language teaching. Annual Review of Applied Linguistics, 32, 111-129. https://doi.org/10.1017/S0267190512000128

Nesselhauf, N. (2003). The use of collocations by advanced learners of English and some implications for teaching. Applied Linguistics, 24(2), 223-242. https://doi.org/10.1093/applin/24.2.223

Peters, E., \& Pauwels, P. (2015). Learning academic formulaic sequences. Journal of English for Academic Purposes, 20, 28-39. https://doi.org/10.1016/j.jeap.2015.04.002

Siepmann, D. (2008). Phraseology in learners' dictionaries: What, where and how? In F. Meunier \& S. Granger (Eds.), Phraseology in foreign language learning and teaching (pp. 185-202). Amsterdam, Netherlands: John Benjamins.

Simpson-Vlach, R., \& Ellis, N. C. (2010). An academic formulas list: New methods in phraseology research. Applied Linguistics, 31(4), 487-512. https://doi.org/10.1093/applin/amp058

University of Oxford Text Archive. (2014). British Academic Written English Corpus. Retrieved from http://ota.ahds.ac.uk/desc/2539

Wray, A. (2009). Future directions in formulaic language research. Journal of Foreign Languages, $32(6), 2-17$. 


\section{Appendix A. A Worksheet Given in Stage 1}

Which of the phrases below goes in which gap?

1.

At the same time

For example

Whether or not

In addition to

I am a member of the badminton club and I enjoy it for

reasons. , the other members are all very friendly, and we often

enjoy joking around together. I I. I they take practicing quite seriously, and are competitive during games. __ _ ___ this, we often travel to other cities to play against other teams, which I like doing. Afterwards, I we win, we enjoy chatting and drinking together.

Which one of the phrases in bold signals:

When things happened?

Addition of similar information?

An example?

An amount?

Uncertainty?

2. In contrast to To some extent
In terms of

In other words
With respect to In order to

If you plan to travel a lot during your holiday in Japan, the JR Rail Pass is definitely worth having. saving you money, it is amazing as you get unlimited travel on the Shinkansen and other trains for as long as you choose. I_ pass and use any train during that time without paying. ease of use, it's also very convenient.

use it, all you have to do is show it at the station. , flying may be quicker; however the Shinkansen are more frequent, and not much slower. Also, I _ flying, you get to see the country as you travel if you go by train.

Which one of the phrases in bold signals:

The same meaning in different words?

Addition of contrasting information?

How something is done?

'Framing' the topic within a new category?

An amount?

'Framing' the topic within a new category?

3.

On the other hand

Can be seen

As well as

As a result

From looking around on the bus or in the classroom, it that smartphones have become very popular. Like older mobile phones, they are able to make calls and send messages. this smartphones have a number of functions that older mobile phones do not have. 
smartphones have made keeping in touch a lot easier. many people now cannot imagine surviving without their smartphones.

They have become too dependent on them. that the telephone changed communication 100 years ago, smartphones are doing it again today.

Which one of the phrases in bold signals:

Addition of contrasting information?

Addition of similar information?

Addition of similar information?

Reference to evidence?

A relation of cause and result?

\section{Appendix B. An Example of a Paragraph Given to Participants for Editing Practice in Stage 2}

There are two reasons why I think Kanazawa is one of the best places in Japan for visitors. The first is Kenrokuen, one of the top three gardens in Japan. There, you can eat delicious food, such as dango and gold foil soft cream which are tasty. You can also enjoy nice scenery in all seasons, for example, in spring, the cherry blossom is amazing, while in summer, everything is green and the flowers are in bloom. In autumn, the leaves turn red, which is beautiful, while in winter, the yukizuri is fantastic. Second, there are many traditional buildings in Kanazawa, such as Kanazawa Castle, which is a beautiful building and is lit up at night. The Ninja Temple is also very interesting because you can see many secret rooms and hidden passages. Therefore, you can enjoy eating good food and visiting interesting and scenic places in Kanazawa.

\section{An Example of an Edited Paragraph}

There are two reasons why I think Kanazawa is one of the best places in Japan for visitors. The first is Kenrokuen, one of the top three gardens in Japan. There, you can eat delicious food, such as dango and gold foil soft cream which are tasty. As well as this, you can also enjoy nice scenery in all seasons, for example, in spring, the cherry blossom is amazing, while in summer, everything is green and the flowers are in bloom. In autumn, the leaves turn red, which is beautiful, while in winter, the yukizuri is fantastic. In addition to Kenrokuen, there are a number of traditional buildings in Kanazawa, such as Kanazawa Castle, which is a beautiful building and is lit up at night. The Ninja Temple is also very interesting because you can see many secret rooms and hidden passages. As a result, you can enjoy eating good food and visiting interesting and scenic places in Kanazawa. 